\title{
EFFECT OF BODY MASS INDEX ON RESULTS OF PERCUTANEOUS NEPHROLITHOTOMY IN THE TREATMENT OF LOWER CALYCEAL STONE > 2CM
}

\begin{tabular}{ll}
\hline Surgery & \\
$\begin{array}{l}\text { Montadhar H. } \\
\text { Nima }\end{array}$ & $\begin{array}{l}\text { Department Of Surgery, Medical College, Baghdad University, Bab Al Mudham, 43300, } \\
\text { Baghdad, Iraq. }\end{array}$ \\
\hline $\begin{array}{l}\text { Shahad A. } \\
\text { Ibraheem* }\end{array}$ & $\begin{array}{l}\text { Department Of Imaging, Faculty Of Medicine And Health Sciences, Universiti Putra } \\
\text { Malaysia, 43400 Serdang, Selangor, Malaysia. * Corresponding Author }\end{array}$ \\
\hline $\begin{array}{l}\text { Titi Rahmawati } \\
\text { Hamedon }\end{array}$ & $\begin{array}{l}\text { Department Of Community, Faculty Of Medicine And Health Sciences, Universiti Putra } \\
\text { Malaysia, 43400 Serdang, Selangor, Malaysia. }\end{array}$ \\
\hline
\end{tabular}

\section{ABSTRACT}

Background: This work was intended to distinguish the results of Percutaneous Nephrolithotomy (PCNL) related to stone-free rates (SFR) by the varying body mass index (BMI) of the patients who subjected for lower calyx stone treatment (with a stone range of $\geq 2 \mathrm{~cm}$ ).

Materials and methods: A total of 287 patients who went through the PCNL for kidney stones were selected for the study. Only patients treated at Shahid-Ghazi Hariri Surgical Specialties Hospital (Medical City) and Al-Qima Private Hospital (Baghdad) within the time frame of January 2015 to April 2018 selected for the study. Information on patients' BMI and SFR was collected and analyzed to compare and contrast the differences in obese patients.

Results: The average age and BMI of the patients are 41 years old and $34 \mathrm{~kg} / \mathrm{m} 2$ respectively. For total mean stone size $2.2 \mathrm{~cm}$. Besides that, the average value for height was $173 \mathrm{~cm}$ and weight $101 \mathrm{~kg}$. The overall stone-free rate was $82 \%$ and the mean hospital stay was $115 \pm 51.21 \mathrm{~min}$, Major complications were seen in 65 patients $(22.6 \%)$. No statistically significant differences were found in SFR, age and stone side among the four groups. The stone-free rates (SFRs) of a single procedure for the groups were $85 \%, 79.3 \%, 79 \%$, and $84 \%$, respectively. Major complications were not observed either during or after the operations.

Conclusion: The effectiveness of PCNL treatment for removal of lower calyceal stone is influenced by the varying patients' BMI value and results in high SFR value.

\section{KEYWORDS}

PCNL; lower calyx ; BMI; SFR

\begin{abstract}
INTRODUCTION
Obesity is a common condition that affects over 300 million people worldwide not just in industrialized but in developing countries as well $[1,2]$. During the last 2 decades, it has been more frequent in clinical practice to encounter obese patients with large renal stones that demand treatment.Obesity has previously been demonstrated as an independent risk factor for urolithiasis because of the increased excretion of calcium, oxalate, sodium, and uric acid in the urine of these patients [3-6].
\end{abstract}

The surgical treatment of renal stones in overweight and obese patients is challenging. Shock wave lithotripsy (SWL) is the treatment of choice for renal stones $2 \mathrm{~cm}$, whereas percutaneous nephrolithotomy (PCNL) is preferred for large or staghorn calculi [7]. However, SWL is often precluded in obese patients due to weight limitations on the table, inability to target the stone due to inadequate fluoroscopic or sonographic imaging, and a skin-to stone distance that exceeds the distance between the point of shock wave generation (F1) and the shock wave focal point (F2), which typically measures $13 \mathrm{~cm}$. In addition, shock wave attenuation by body fat undoubtedly has some effect on the efficiency of stone fragmentation [8]. Consequently, PNL may constitute the first line of treatment for renal stones in obese patients [9].

Although the safety of PCNL has been shown in obese patients, the procedure was found to be associated with a longer operative time, a lower stone-free rate (SFR), and higher intervention rate [5]. Additionally, some investigators have reported a longer hospital length of stay (LOS) and a higher complication rate after PCNL in these patients $[10,11]$. To our knowledge, very few published series have addressed the safety and efficacy of PNL in obese patients [12-15] and most of these publications included small numbers of patients $[12,14$, $15]$

This led us to review our contemporary PCNL outcomes stratified by body mass index (BMI) to determine the effectiveness and safety of using this approach in treating obese patients.

\section{RESEARCH METHODS AND PROCEDURE}

The computerized data of 287 patients who underwent within the time frame of January 2015 to April 2018 in Shahid-Ghazi Hariri Surgical
Specialties Hospital (Medical City) and Al-Qima Private Hospital (Baghdad, Iraq) were reviewed retrospectively. Patients were computerized selected from urology department with age group of 20 years to 70 years old.

All Patients were stratified into four groups according to the World Health Organization (WHO) classification of body mass index (BMI) [15]: $<25$ (group1, average), 25-29.9 (group2, overweight), 30-39.9 (group 3, obese), and $>40 \mathrm{~kg} / \mathrm{m} 2$ (group 4, morbidly obese). Preoperative evaluation of the patients included history, clinical examination, and measurement of serum creatinine, complete blood picture, coagulation profile, and liver function tests.

Radiologic investigations included plain abdominal x-ray (kidneyureters-bladder [KUB]), ultrasonography (US), and non-contrast computed tomography (NCCT) in patients with radiolucent stones. Stone size was determined by measuring its longest diameter on preoperative radiologic investigations.

The results obtained were used to distinguish among BMI groups. The duration of surgery and hospitalization was also taken into count. Patients with stone size $\geq 2 \mathrm{~cm}$ without any abnormality on the genitourinary tract. Those with stones less than $2 \mathrm{~cm}$, aged less than 20 , pregnant women and with high bleeding tendency were excluded from the study. Besides that patient diagnosed with multiple renal stones, renal pelvic stone, renal stones in the anomalous kidney and renal failures were also excluded.

Prior to the treatment process, all the patients were entitled to standard fluoroscopy-guided renal access. It was performed as the patient lying flat after the retrograde ureteric catheterization, under the influence of general anesthesia. It was performed by a surgeon well versed in endourological procedures. To ensure the accuracy of puncture fluoroscopically and to distend the pelvicalyceal system, the retrograde $5 \mathrm{~F}$ catheter was used. It was done by contrast injecting that delineates the posterior calyx precisely.

Each patient was subjected to $10 \mathrm{mg}$ of furosemide, i.v bolus diuretic injection before initiating the treatment procedure. Past medical histories proved that furosemide has the tendency of sustaining and uniformly distance pelvicalyceal system throughout the treatment 
duration. Besides that, furosemide also plays an essential role as a supplement for the installation of the saline through the retrograde catheter. The initial puncture was made using biplanar-C arm fluoroscopy. The nephroscope used were storz adult size with $24,26 \mathrm{fr}$, Coaxial telescopic dilators (30F) and Amplatz sheath were used to dilate the tract. For obese and morbidly obese patients, a bigger skin incision was done, matching the level of abdominal fascia. This is to gain approachable distance towards the stone.

Nephroscopy was done to identify the stones using a rigid nephroscope. Similar with previous procedure, longer Amplatz sheath and nephroscope was used for obese and morbidly obese patients. While the removal of small stones done by using forceps, pneumatic lithotripters approach was used to disintegrate large stones. At the end of treatment, a $22 \mathrm{~F}$ nephrostomy tube was placed. The SFR was validated by using non-contrast approach, $5-\mathrm{mm}$ slice CT or nephrotomograms to affirm that the stone has been removed completely. Throughout the follow-up process, all the complications faced by patients were recorded.

Patients that were observed with a significant amount of residual calculi went to repeat PCNL or to ESWL session immediately (within 48 to 73 hours) after the first treatment. Meanwhile, for those observed with no residual stones, the tube was removed after 2 days and discharged when no any other complications arise. Patients were observed for the subsequent 3 months and minimum once a year for follow-up treatment. For every visit, KUB and US were conducted and NCCT was done in patients with radiolucent stones.

Results obtained were analyzed by a descriptive statistical approach using IBM SPSS Statistics Software (Ver. 25). The t-test was used for continuous variable analysis and chi-square was used for comparative analysis. Results presented in the form of percentage, average and standard deviations. One-way analysis of variance (ANOVA) was used to differentiate the 4 groups of BMI meanwhile logistic regression was used to multivariate analysis. Hosmer-Lemeshow Odd Ratio test was used to compute the odds ratios of SFR by BMI. Any pvalue less than 0.05 was assumed as statistically significant. This research had attained approval from the ethics committee of surgery department on Baghdad Iraq medical college. Patients were informed on the research prior treatment

\section{RESULTS}

Totally, 287 patients were subjected for PCNL treatment from January 2015 until April 2018 at Shahid-Ghazi Hariri Surgical Specialties Hospital and Al-Qima Private Hospital, consisting of 171 (60\%) male and $116(40 \%)$ female patients with a mean age of $41 \pm 13.24 \mathrm{yrs}$ (range: $20-70 \mathrm{yr}$ ), Mean stone size was $2.2 \pm 4.45 \mathrm{~cm}$ (range: $2.1-2.9$ $\mathrm{cm}$ ). Mean patient height was $173 \pm 5.23 \mathrm{~m}$ (range: $158-188 \mathrm{~cm}$ ), and mean weight was $101 \pm 25.89 \mathrm{~kg}$ (range: $58-145 \mathrm{~kg}$ ). Of the patients, the overall mean BMI was $34 \pm 8.36 \mathrm{~kg} / \mathrm{m}^{2}$ (range, $20-54 \mathrm{~kg} / \mathrm{m}^{2}$ ). Among 287 patients, we found 77 with normal BMI, 53(18.5\%) with average, 58(20.2\%) with overweight, $89(31 \%)$ with obesity, and $87(30.3)$ to be morbidly obese. Table 1 shows preoperative characteristics of these groups.

There were no statistically significant difference among the groups for stone side and age, a higher incidence of male patients in the morbidly obese group in comparison to the remaining three groups was statistically significant, the mean stone size were $1.7 \pm 2.14 \mathrm{~cm}$ in average group, $1.7 \pm 2.44 \mathrm{~cm}$ in overweight, $2.3 \pm 2.52 \mathrm{~cm}$ in obese group and $2.6 \pm 2.32 \mathrm{~cm}$ in morbidly obese and the four groups were statistically significant $P$ value $<0.001$.

Table 2: comparison of the Body Mass Index on Outcome
Table 1: comparison of the Body Mass Index with respect to demographic data

\begin{tabular}{|c|c|c|c|c|c|}
\hline \multirow[t]{2}{*}{ Variables } & \multicolumn{4}{|c|}{ BMI } & \multirow{2}{*}{$\begin{array}{l}P \\
\text { value }\end{array}$} \\
\hline & $\begin{array}{c}\text { Average } \\
(<25)\end{array}$ & \begin{tabular}{|c|} 
Overweight \\
$(25-29.9)$
\end{tabular} & $\begin{array}{c}\text { Obese } \\
(30-39)\end{array}$ & $\begin{array}{c}\text { Morbidly } \\
\text { Obese } \\
(>40)\end{array}$ & \\
\hline $\begin{array}{l}\text { Gender } \mathbf{N}(\%) \\
\text { Male } \\
\text { female } \\
\text { Stone side } \mathbf{N}(\%)\end{array}$ & $\begin{array}{l}25(14.6) \\
28(24.1)\end{array}$ & $\begin{array}{l}42(24.6) \\
16(13.8)\end{array}$ & $\begin{array}{l}37(21.6) \\
52(44.8)\end{array}$ & $\begin{array}{l}67(39.2) \\
20(17.2)\end{array}$ & $\begin{array}{c}0.001 \\
*\end{array}$ \\
\hline $\begin{array}{l}\text { Right } \\
\text { Left }\end{array}$ & $\begin{array}{c}26(17) \\
27(20.1)\end{array}$ & $\begin{array}{l}33(21.6) \\
25(18.7)\end{array}$ & $\begin{array}{l}53(34.6) \\
36(26.9)\end{array}$ & $\begin{array}{l}41(26.8) \\
46(34.3)\end{array}$ & $0.33 *$ \\
\hline $\begin{array}{l}\text { Age yrs } \\
\text { Mean } \pm \text { SD } \\
\text { Range }\end{array}$ & $\begin{array}{c}36 \pm 12.29 \\
(20-70)\end{array}$ & $\begin{array}{c}41 \pm 11.73 \\
(20-70)\end{array}$ & $\begin{array}{l}43 \pm 14.0 \\
(20-70)\end{array}$ & \begin{tabular}{|c|}
$41 \pm 13.47$ \\
$(20-70)$
\end{tabular} & $0.62 \dagger$ \\
\hline $\begin{array}{l}\text { Stone size, } \mathbf{c m} \\
\text { Mean } \pm \mathrm{SD} \\
\text { Range }\end{array}$ & $\begin{array}{l}1.7(2.14) \\
(1.2-2.0)\end{array}$ & $\begin{array}{l}1.7(2.44) \\
(1.3-2.3)\end{array}$ & $\begin{array}{l}2.3(2.52) \\
(1.7-2.8)\end{array}$ & $\begin{array}{l}2.6(2.32) \\
(2.0-2.9)\end{array}$ & $\begin{array}{c}0.001 \\
\dagger\end{array}$ \\
\hline $\begin{array}{l}n=\text { number of } \\
* X^{2} \text { and } \varphi \text { ANO } \\
\text { variables, resp }\end{array}$ & its. & & & & \\
\hline
\end{tabular}

Postoperative outcomes of the groups are listed in Table 2. The mean operative time was $64 \pm 38.39$ minutes in average group , $96 \pm 50.21$ minutes in overweight group, $132 \pm 41.88$ minutes in obese group and $142 \pm 38.59$ minutes in morbidly obese group and the four groups were statistically significant $P$ value $<0.04$. The SFR after a single procedure for the 4 groups were $85 \%, 79.3 \%, 79 \%$, and $84 \%$, respectively (P $=0.6$ ). Total mean fluoroscopy time was $56 \pm 12.09$ seconds and it was statistically different among groups $p<0.03$.

In average group, 27 patients underwent auxiliary treatments (21 patients with ESWL and 6 patients with a repeat PCNL), in overweight group, 30 patients underwent additional treatments (18 patients with ESWL and 12 patients with a second PCNL), in obese group, 45 patients underwent additional treatments (26 patients with ESWL and 19 patients with a second PCNL), and in morbidly obese group, 10 patients underwent additional treatments (3 patients with ESWL and 7 patients with a second PCNL).. There were significant differences among the groups in Auxiliary procedures. Major complications were seen in 65 patients $(23 \%)$ and included significant hematuria $34(11.8 \%)$, ureteric obstruction by stone fragments in $25(8.7 \%)$, colonic injury $4(1.4 \%)$ and failed access in 2 . Ureteric stone fragments were managed by a second-look PCNL. The patient in whom PCNL was deemed unsuccessful because of access failure was managed by open surgery.

Colonic injury was successfully treated by conservative management. No emergent operative intervention was needed because all injuries were retroperitoneal. The initial management included withdrawal of the nephrostomy tube outside the kidney and colon to the retroperitoneal space, insertion of a double-J ureteral stent, anal dilation, total parenteral nutrition, bowel rest, and intravenous antibiotics (cephalosporins and metronidazole) for $7 \mathrm{~d}$. This conservative management was successful in all patients. The mean hospital stay was $54 \pm 18.13 \mathrm{hrs}$ (range: $18-82$ ).

After univariate and bivariate analyses, chi square and one way ANOVA analysis confirmed the absence of significant association between BMI groups with SFR. Postoperative operative time and hospital stay increases along with BMI $(\mathrm{P}<0.001$ and $\mathrm{P}<0.001$, respectively). Significant differences among groups in terms of fluoroscopy time, hospital stay and need for auxiliary procedures were found. Morbidly obese group patients appear to have slightly less complications, along with a SFR higher than overweight and obese patients.

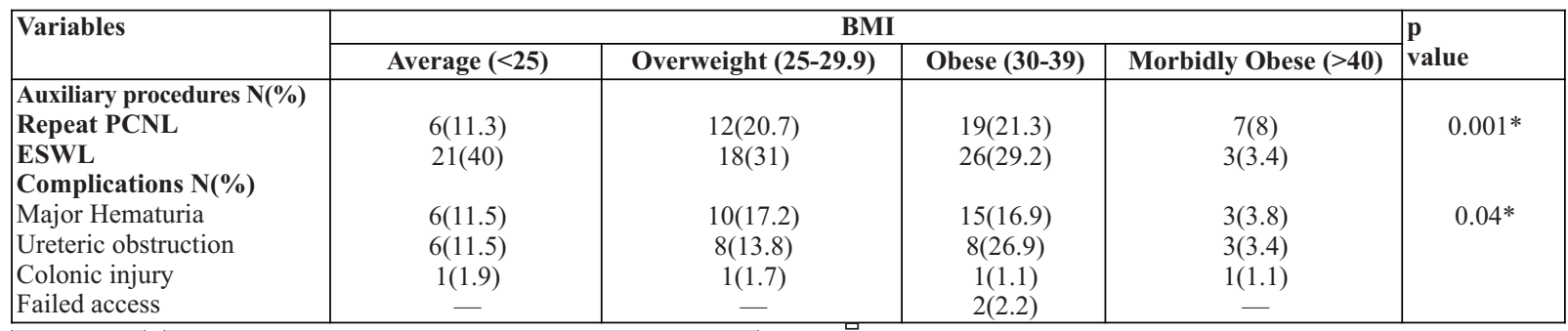




\begin{tabular}{|c|c|c|c|c|c|}
\hline $\begin{array}{l}\text { Stone free } \mathbf{N}(\%) \\
\text { Fluoroscopy time, sec } \\
\text { Mean } \pm \text { SD } \\
\text { Range } \\
\text { Operative duration, min } \\
\text { Mean } \pm \text { SD } \\
\text { Range } \\
\text { Hospital stay , hrs } \\
\text { Mean } \pm \text { SD } \\
\text { Range }\end{array}$ & $\begin{array}{c}45(85) \\
52 \pm 12.58 \\
(30-82) \\
64 \pm 38.39 \\
(30-142) \\
42 \pm 17.77 \\
(18-77)\end{array}$ & $\begin{array}{c}46(79.3) \\
58 \pm 10.39 \\
(39-90) \\
\\
96 \pm 50.21 \\
(30-170) \\
50 \pm 17.99 \\
(21-77)\end{array}$ & $\begin{array}{c}70(79) \\
57 \pm 11.70 \\
(30-90) \\
132 \pm 41.88 \\
(56-170) \\
57 \pm 16.59 \\
(20-82)\end{array}$ & $\begin{array}{c}73(84) \\
55 \pm 12.54 \\
(30-98) \\
142 \pm 38.59 \\
(56-175) \\
61 \pm 14.91 \\
(20-80)\end{array}$ & $\begin{array}{c}0.7^{*} \\
0.03 \dagger\end{array}$ \\
\hline
\end{tabular}

n = number of units.

$* \mathrm{X}^{2}$ and $\uparrow$ ANOVA tests were used for categorical and continuous variables, respectively.

\section{DISCUSSION}

Urinary stone treatment changes over the year enable endoscopic techniques to be performed in most of the cases. The frequency of urolithiasis fluctuates differs in literature influencing $5-15 \%$ of the global population [17]. The parallel increase in obese and morbid obese cases over the decades has triggered acceleration in stone disease among the population $[18,19]$.

Previous research also indicates that obese patients suffering from urolithiasis double than non-obese patients. The recurrence rates are almost $50 \%$ [20]. On the other hand, mismatching information and the improvement of new endoscopic instruments caused the ideal administration of stone infection for the patients unconcluded. PCNL is one of the options available for treatment of stone for obese patients, which has given effective results without influenced by BMI. In an investigation of 114 patients stratified by perfect body weight, overweight, obese and morbidly obese, there was no contrast among the groups and the SFR was $90 \%$ [21].

Despite the fact that the existing research illustrated PCNL for obese and morbidly obese patients achieves a comparable SFR rate with nonobese patients, there are significant technical difficulties faced while performing PCNL to such patients. Positioning, puncture, operation duration, ureteroscopy are examples of technical difficulties faced while PCNL for these patients.

This study showed that the population selected for research consists of obese and morbidly obese patients mostly. Patients in the obese and morbidly obese group are generally males with stone size $\geq 2 \mathrm{~cm}$. Patients with average BMI (53\%) and overweight BMI (58\%) are exposed to high risk of diet-related diseases, mostly male patients.

According to [22], a comparative study using 44 obese patients (30 at $20-50 \%$ and 14 at $>50 \%$ over ideal body weight) and 226 non-obese patients revealed that there are no significant differences for all the parameters experimented. The experimented parameter comprises duration of operation, hospitalization, SFR after the PCNL treatment. The author acknowledged that no specific measure is needed to evaluate the stones for obese patients. Similarly, in this study, SFR was positively significant for all BMI groups, indicating that the study is acceptable. Another study by [23] exposed that among 57 patients with $\mathrm{BMI}>30 \mathrm{~kg} / \mathrm{m}^{2}$, the duration of operation was longer, which is similar to this study.

In the context of hospitalization, there is difference spotted among the BMI groups. A research by [23] stated that treatment procedures for single puncture were similar for all the 530 patients that include 93 obese patients. However, the rate of complexity was $37 \%$ for the morbidly obese category and $17 \%$ for BMI $\geq 40 \mathrm{~kg} / \mathrm{m}^{2}$. This study also similar to the study by [23] as a single puncture for obese and morbidly obese patients included technical complexity such as longer scope to reach the stone.

The depth of the subcutaneous tissue in the morbidly obese patient may mean that standard PCNL instruments are too short to reach the stone. Curtis et al [24] described a technique of incising the skin and fat, down to the muscular fascia, to gain the extra length required to reach the stone. A second technique involves inserting a $12 \mathrm{~F}$ nephrostomy tube, allowing the tract to mature for a week, and then using a flexible cystoscope and electrohydraulic probe to treat the stone [25]. Giblin et al [26] reported the use of a long 32F Amplatz sheath in combination with a $30 \mathrm{~F}$ gynaecologic laparoscope $27 \mathrm{~cm}$ long to treat stones in the morbidly obese patients.
Carson et al [22] compared their experience with PCNL in 44 obese patients to 226 non obese patients. They found no significant difference among the three groups for any of the parameters evaluated, including operating time, need for secondary procedures, hospital stay, complication rate, and stone-free rate. Indeed, the authors noted that no special measures were required to access the kidney or stones in these obese patients.

Pearle et al [23] showed that in 57 patients with a BMI of $>30 \mathrm{~kg} / \mathrm{m} 2$ the operative time was slightly longer but outcomes in terms of stone-free and complication rates were not different compared to 179 patients with a BMI of $<30 \mathrm{~kg} / \mathrm{m} 2$. Faerber et al [27] described their experience of PNL in 530 patients, including 93 defined as morbidly obese. They found that for procedures requiring a single puncture the operating times were similar across the groups and stone-free rates were comparable, but the complication rate was $37 \%$ in the morbidly obese compared with $17 \%$ in patients with a BMI of $<40 \mathrm{~kg} / \mathrm{m} 2$.

In a study of 181 patients who were stratified into four groups according to their BMI, Koo et al [28] did not find statistically significant differences in operative duration, decrease in hemoglobin concentration, postoperative analgesic use, hospital stay, and stonefree rates, nor was there a higher complication rate in obese patients, in contrast the result of our study cannot fit with previous studies in the term of Auxiliary procedures, Complications, Fluoroscopy time, Operative duration and hospital stay, Also our results are comparable with other contemporary series of PCNL in obese and morbidly obese patients [26-28]. In addition, our study confirms the finding that PCNL in obese and morbidly obese patients has a complication rate and hospital stay similar to those achieved in non-obese populations.

In our study, the fluoroscopy time in the overweight and obese groups were little longer than other groups probably affected by the high stone burden. We performed the whole process guided by fluoroscopy, the time begins with the confirmation of the surgical place and ends with the placement of the nephrostomy tube. Poor visualization in obese patients makes it difficult to gain access to the kidney and this could increase total fluoroscopy time and radiation exposure. We found that the fluoroscopy time was significant different among groups.

In our study, the morbidly obese group appears to do slightly better in terms of stone clearance and complication rate than normal weight patients. The 4 groups being homogeneous in terms of preoperative and stone characteristics and most of the intraoperative details, one possible explanation could be the surgeons in this group. Most of the procedures were done by our most experienced surgeons on morbidly obese patients, fearing complications and trying to avoid the necessity of auxiliary procedures.

The differences of average BMI and SFR were measurably not significant. Hence, the impact on the average BMI of the whole patients predicted to be huge. This research compared the patients by categorizing them into BMI range to emphasize the impact of BMI on the PCNL and SFR rate. The present study has some limitations. First, our study is a retrospective analysis. Second, because of the limited number of patients for power analysis, the results may lack reaching a statistically significant difference between obese and normal weight patients.

\section{CONCLUSIONS}

The results obtained proved that the effectiveness of PCNL treatment is influenced by the BMI of the patient. Percutaneous nephrolithotomy in obese and morbidly obese patients yields a stone-free rate that is not comparable to that achieved in non-obese ones. 
The complication rate, need for auxiliary procedures, transfusion rate, and hospital stay are also similar. Obesity does not increase complications in PCNL, and the efficacy of the technique is similar to normal weight patients in high-volume centers with appropriate expertise in this condition. Total operative time and radiation exposure increases along with BMI, putting patients at risk.

\section{REFERENCES}

1. Finucane, M. M., Stevens, G. A., Cowan, M. J., Danaei, G., Lin, J. K., Paciorek, C. J., ... \& Farzadfar, F. (2011). National, regional, and global trends in body-mass index since 1980: systematic analysis of health examination surveys and epidemiological studies with 960 country-years and $9 \bullet 1$ million participants. The Lancet, 377(9765), 557-567.

2. Aboumarzouk, O. M., Somani, B., \& Monga, M. (2012). Safety and efficacy of ureteroscopic lithotripsy for stone disease in obese patients: a systematic review of the ureteroscopic lithotripsy for stone disease in obese patients: a systematic review of the

3. Türk, C., Knoll, T., Petrik, A., Sarica, K., Skolarikos, A., Straub, M., \& Seitz, C. (2015). Guidelines on urolithiasis. Eur Urol, 40, 362-371.

4. Curhan, G. C. (2007). Epidemiology of stone disease.Urologic Clinics of North America, 34(3), 287-293.

5. Ekeruo, W. O., Tan, Y. H., Young, M. D., Dahm, P., Maloney, M. E., Mathias, B. J., ... \& Preminger, G. M. (2004). Metabolic risk factors and the impact of medical therapy on the management of nephrolithiasis in obese patients. The Journal of urology, 172(1), 159163.

6. Fuller, A., Razvi, H., Denstedt, J. D., Nott, L., Pearle, M., Cauda, F., ... \& CROES PCNL Study Group. (2012). The CROES percutaneous nephrolithotomy global study: the influence of body mass index on outcome. The Journal of urology, 188(1), 138-144.

influence of body mass index on outcome. The Journal of urology, 188(1), 138-144.
7. Skolarikos, A., Alivizatos, G., \& De La Rosette, J. J. M. C. H. (2005). Percutaneous nephrolithotomy and its legacy.European Urology, 47(1), 22-28.

8. Thomas, R., \& Cass, A. S. (1993). Extracorporeal shock wave lithotripsy in morbidly obese patients. The Journal of urology, 150(1), 30-32.

9. Choban, P. S., \& Flancbaum, L. (1997). The impact of obesity on surgical outcomes: a review. Journal of the American College of Surgeons, 185(6), 593-603.

10. Olbert, P. J., Hegele, A., Schrader, A. J., Scherag, A., \& Hofmann, R. (2007). Pre-and perioperative predictors of short-term clinical outcomes in patients undergoing perioperative predictors of short-term clinical outcomes in patien

11. Tefekli, A., Kurtoglu, H., Tepeler, K., Karadag, M. A., Kandirali, E., Sari, E., ... \& Tefekli, A., Kurtoglu, H., Tepeler, K., Karadag, M. A., Kandirali, E., Sari, E., ... \&
Muslumanoglu, A. Y. (2008). Does the metabolic syndrome or its components affect the outcome of percutaneous nephrolithotomy?. Journal of endourology,22(1), 35-40.

12. Koo, B. C., Burtt, G., \& Burgess, N. A. (2004). Percutaneous stone surgery in the obese: outcome stratified according to body mass index. BJU international, 93(9), 1296-1299.

13. El-Assmy, A. M., Shokeir, A. A., El-Nahas, A. R., Shoma, A. M., Eraky, I., El-Kenawy, M. R., \& El-Kappany, H. A. (2007). Outcome of percutaneous nephrolithotomy: effect of body mass index. European urology, 52(1), 199-205.

14. Tomaszewski, J. J., Smaldone, M. C., Schuster, T., Jackman, S. V., \& Averch, T. D. (2010). Outcomes of percutaneous nephrolithotomy stratified by body mass index.Journal of endourology, 24(4), 547-550.

15. Alyami, F. A., Skinner, T. A., \& Norman, R. W. (2013). Impact of body mass index on clinical outcomes associated with percutaneous nephrolithotomy. Canadian Urological Association Journal, 7(3-4), E197.

16. World Health Organization. Obesity: preventing and managing the global epidemic. Geneva, Switzerland: WHO, 2000. WHO Technical Report Series, 894

17. Moe, O. W. (2006). Kidney stones: pathophysiology and medical management. The Lancet, 367(9507), 333-344.

18. Stamatelou, K. K., Francis, M. E., Jones, C. A., Nyberg Jr, L. M., \& Curhan, G. C. (2003). Time trends in reported prevalence of kidney stones in the United States: 1976-19941. Kidney international, 63(5), 1817-1823.

19. Ogden, C. L., Carroll, M. D., Curtin, L. R., McDowell, M. A., Tabak, C. J., \& Flegal, K. M. (2006). Prevalence of overweight and obesity in the United States, 1999-2004. Jama, 295(13), 1549-1555.

20. Sutherland, J. W., Parks, J. H., \& Coe, F. L. (1985). Recurrence after a single renal stone in a community practice. Mineral and electrolyte metabolism, 11(4), 267-269.

21. Alyami FA, Skinner TA, Norman RW: Impact of BMI on clinical outcomes associated with PNL. Can Urol Assoc J. 2012;15: 1-5.

22. Carson III, C. C., Danneberger, J. E., \& Weinerth, J. L. (1988). Percutaneous lithotripsy in morbid obesity. The Journal of Urology, 139(2), 243-245.

23. Pearle, M. S., Nakada, S. Y., Womack, J. S., \& Kryger, J. V. (1998). Outcomes of contemporary percutaneous nephrostolithotomy in morbidly obese patients. The Journal of Urology, 160(3), 669-673.

24. Curtis, R., Thorpe, A. C., \& Marsh, R. (1997). Modification of the technique of percutaneous nephrolithotomy in the morbidly obese patient. British journal of urology, 79(1), 138-140.

25. Segura, J. W. (1990). Role of percutaneous procedures in the management of renal calculi. The Urologic clinics of North America, 17(1), 207-216.

26. Giblin, J. G., Lossef, S., \& Pahira, J. J. (1995). A modification of standard percutaneous nephrolithotripsy technique for the morbidly obese patient. Urology, 46(4), 491-493

27. Faerber, G. J., \& Goh, M. (1997). Percutaneous nephrolithotripsy in the morbidly obese patient. Techniques in Urology, 3(2), 89-95.

28. Koo, B. C., Burtt, G., \& Burgess, N. A. (2004). Percutaneous stone surgery in the obese: Koo, B. C., Burtt, G., \& Burgess, N. A. (2004). Percutaneous stone surgery in the obese:
outcome stratified according to body mass index. BJU international, 93(9), 1296-1299. 